\title{
Occult Incontinence in Women with Pelvic Organ Prolapse - DOES IT MATTER?
}

\author{
K. Jundt ${ }^{1}$, S. Wagner ${ }^{1}$, V. von Bodungen ${ }^{1}$, K. Friese ${ }^{1}$, U. M. Peschers ${ }^{2}$ \\ ${ }^{1}$ I. Department of Obstetrics and Gynecology, Beckenbodenzentrum der LMU, Ludwig-Maximilians-Universität, Munich, Germany, \\ ${ }^{2}$ Beckenboden Zentrum München, Chirurgische Klinik München-Bogenhausen, Munich, Germany
}

\begin{abstract}
Objective: Many surgeons perform an anti-incontinence procedure during prolapse surgery in women in whom occult stress urinary incontinence has been demonstrated. Others prefer a two-step approach. It was the aim of the study to find out how many women really need a second operation and if a positive cough stress test with the prolapse reduced is associated with the development of stress urinary incontinence after prolapse surgery.

Methods: 233 women were operated for primary or recurrent prolapse without complaining of SUI. Preoperatively, 53/233 women had a full urogynecological workup with the prolapse reduced. Postoperatively, if the patient suffered from stress urinary incontinence, an anti-incontinence surgery was performed.

Results: 19/53 (35.8\%) women who had a stress test with the prolapse reduced before surgery were defined as occult stress incontinent. Only 3 women $(15.8 \%)$ of these 19 women developed symptoms of incontinence after prolapse surgery and had to be operated because of that. $18 / 233(7.7 \%)$ complained of SUI 6 weeks to 6 months after surgery and received a TVT-tape.

Conclusion: The incidence of stress urinary incontinence manifesting after prolapse surgery is low in this study with $7.7 \%$. This fact and the possible severe side effects of an incontinence operation justify a two-step approach if the patient is counseled and agrees. However, there is a small subgroup of women (3/19, $15.8 \%$ ) with preoperative OSUI and SUI after surgery, who would benefit from a one-step approach. Further research is required to identify these women before surgical intervention.

Key words: occult incontinence; pelvic organ prolapse; prolapse surgery; two step approach

Abbreviations: SUI - stress urinary incontinence, OSUI - occult stress urinary incontinence, TVT - tensionfree vaginal tape, ICS - International Continence Society
\end{abstract}

\section{INTRODUCTION}

If a woman with pelvic organ prolapse leaks only when the prolapse is reduced this is called occult stress urinary incontinence (OSUI). Urethral kinking or external urethral compression may be the underlying cause (Long et al. 2004). The prevalence of OSUI in women with severe genitourinary prolapse varies from $27-68 \%$ in literature (Hextall et al. 1998, Romanzi et al. 2002). According to the recommendations of the International Continence Society, a urodynamic investigation should be part of the diagnostic workup in patients with genital prolapse grade II or more, who are candidates for surgical correction (Karram 1993, Bump et al. 1996). The urodynamic investigation aims to confirm the presence of self-reported stress incontinence and to detect occult stress incontinence. Different tests to reveal this kind of incontinence preoperatively are described: the prolapse may be reduced by using a pessary, a speculum or a swab forceps, then a cough test during urodynamic testing is performed in the lying or standing position. If stress incontinence occurs, surgeons use basically two different kinds of strategies: some prefer to include an anti-incontinence procedure during the prolapse repair, others prefer a two-step approach: firstly, the prolapse is repaired and few months later - after renewed urodynamic testing the patient comes in for incontinence surgery, if necessary. The combination of prolapse and stress incontinence surgery has the advantage to potentially solve two problems at the same time and, thus, to avoid a second operation. However, the combined approach carries an increased risk of side-effects, of which development of obstructive voiding symptoms, bladder retention, and detrusor overactivity are the most important ones (Klutke et al. 2000, de Tayrac et al. 2004).

The advocators of a combination of both surgical procedures state that correction of the genital prolapse itself does not solve the problem of stress incontinence (Roovers et al. 2007).

It was the aim of our study to find out how many women really need a second operation after prolapse surgery and if a positive cough stress test with the prolapse reduced is associated with the development of postoperative SUI.

\section{MATERIAL AND METHODS}

Between January 2004 and July 2005, 233 women were operated for primary or recurrent prolapse in both of our hospitals - I. Department of Obstetrics and Gynecology, Ludwig-Maximilians-University, Munich and Department of Obstetrics and Gynecology, Dachau and were included in our study. Including criteria for 
our longitudinal, observational study were: genital prolapse grade II or higher according to ICS criteria (Bump et al. 1996), no evidence of stress urinary incontinence, sufficient language ability and written informed consent. Therefore every woman with planned prolapse surgery and no sign of stress urinary incontinence (SUI) was included.

The diagnosis of stress urinary incontinence (SUI) was evaluated using a non-validated questionnaire since no validated questionnaire on urinary and anal incontinence was available in German language at the time the study was performed. Furthermore, women were asked in detail for symptoms of SUI.

Preoperatively, 53/233 women, who were recruited in the university department, had a full urogynecological workup including a cough stress test in the standing position with the prolapse reduced with a speculum. If the woman leaked during this test it was defined as positive. Also a complete urodynamic testing was performed in these 53 women. The remaining 180 women, who were recruited in the other department, received a careful urogynecologic examination (measurement of the prolapse according to the ICS criteria) without a cough stress test or urodynamic testing.

Following the two-step strategy, only prolapse repair was performed by either a vaginal or an abdominal approach. Vaginal primary prolapse repair included a hysterectomy combined with anterior or posterior colporrhaphies if necessary and a sacrospinous fixation when the cervix prolapsed down to the hymen or more. Abdominal primary repair included a laparoscopic supracervical hysterectomy with sacral cervicopexy or a complete hysterectomy with sacral colpopexy in combination with a lateral colposuspension. In the case of recurrent prolapse, the vaginal approach included a sacrospinous fixation of the vaginal vault combined with anterior and posterior repair as needed, the abdominal approach included a sacral colpopexy of the vaginal vault prolapse. The decision between both surgical approaches was based on age, sexual activity, and primary or recurrent situation. The abdominal approach was generally preferred in younger women who still had sexual intercourse on a regular base.

Postoperatively, all women received vaginal estrogen therapy for 6 weeks and returned to the urogynecological clinic 6 weeks to 6 months after surgery. If a stress urinary incontinence was found using the same questionnaire as before, a cough stress test and, separately, multichannel urodynamic testing including retrograde cystometry with a filling speed of $50 \mathrm{ml} / \mathrm{min}$ and urethral pressure profilometry with an 8-Fr-microtip catheter at rest (Dantec Duet DU 5500 MK2, Skorlunde, Denmark) was performed according to the ICS standardisation and following the guidelines of the German society for gynaecology and obstetrics (DGGG). The cough stress test with a standardized bladder filling of $300 \mathrm{ml}$ was graded according to the urinary loss: grade 1 - urinary loss of a few drops during vigorous coughing in the standing position, grade 2 - a spurt of urine in the standing or drops of urine in the supine position, and grade 3 - a spurt of urine in the supine position (Schüssler et al. 1983).

An anti-incontinence surgery, e.g. a TVT-procedure or a Burch colposuspenion, was performed when con- servative management of the stress incontinence was ineffective or not appropriate.

Statistical evaluation was performed using the program SPSS (Statistics Package for the Social Science) for Windows Version 15.0 (SPSS Inc., Chicago, USA): Student t-test (for metric parameters) and Wilcoxon signed rank test (for ordinal parameters). $\mathrm{P}<.05$ was defined as significant.

\section{RESULTS}

The mean age of our 233 patients was 62.8 years (range 37 - 88 years). 24/233 (10.3\%) women were premenopausal, 209/233 (89.7\%) peri- or postmenopausal.

All women included in our study had a prolapse of the anterior compartment, in some cases combined with a prolapse of the central or posterior compartment.

The different (vaginal or abdominal) approaches with respect to the primary or recurrent situation are summarized in Table 1 . Three of the 165 women with recurrent prolapse had a Burch colposuspension, and $20 / 165$ had an anterior colporrhaphy in association with their previous prolapse surgeries.

Table 1. Surgical approach.

\begin{tabular}{lcc}
\hline & $\begin{array}{c}\text { vaginal } \\
\text { (with anterior } \\
\text { colporrhaphy) }\end{array}$ & $\begin{array}{c}\text { abdominal } \\
\text { (with lateral) } \\
\text { colposuspension }\end{array}$ \\
\hline Primary situation $(\mathrm{n}=68)$ & 63 & 5 \\
Recurrent situation $(\mathrm{n}=165)$ & 72 & 93 \\
\hline
\end{tabular}

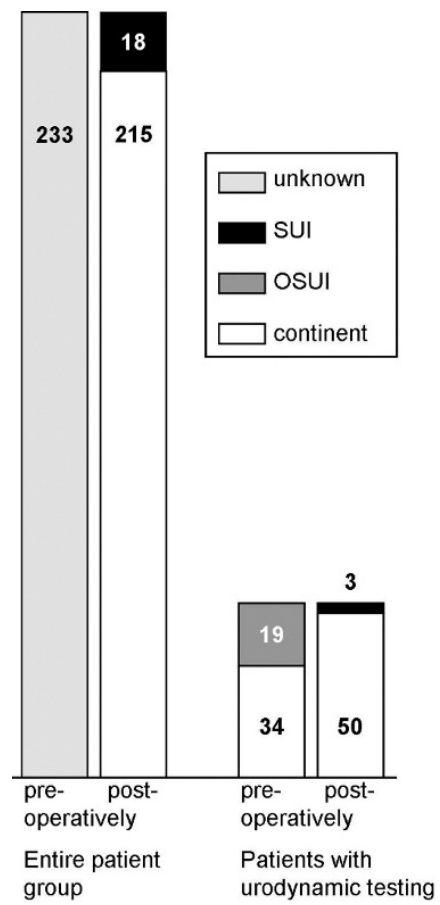

Fig. 1. Preoperative diagnosis and postoperative outcome in all patients (1.h.s.) and in the patient sub-group with urodynamic testing (r.h.s.). 
Table 2. Preoperative diagnosis and postoperative results after prolapse repair.

\begin{tabular}{lccc}
\hline & OSUI preoperatively & $\begin{array}{c}\text { SUI postoperatively } \\
\text { (subjectively) }\end{array}$ & TVT surgery after 6w-6mo \\
\hline $\begin{array}{l}\text { Patients with urodynamic } \\
\text { testing (n=53) }\end{array}$ & $19 / 53(35.8 \%)$ & $5 / 53(9.4 \%)$ & $3 / 53(5.7 \%)$ \\
$\begin{array}{l}\text { Patients without } \\
\text { urodynamic testing }(\mathrm{n}=180)\end{array}$ & - & $26 / 180(14.4 \%)$ & $15 / 180(8.3 \%)$ \\
Entire patient group $(\mathrm{n}=233)$ & - & $31 / 233(13.3 \%)$ & $18 / 233(7.7 \%)$ \\
\hline
\end{tabular}

Table 3. Urodynamic parameters of women with and without OSUI preoperatively.

\begin{tabular}{|c|c|c|c|c|c|}
\hline $\mathrm{n}=53$ & $\begin{array}{c}\text { Max. bladder } \\
\text { capacity } \\
{[\mathrm{ml}]} \\
\text { mean }\end{array}$ & $\begin{array}{c}\text { Residual urine } \\
\text { after reposition } \\
{[\mathrm{ml}]} \\
\text { mean }\end{array}$ & $\begin{array}{l}\text { First bladder } \\
\text { sensation } \\
{[\mathrm{ml}]} \\
\text { mean }\end{array}$ & $\begin{array}{l}\text { Max. urethral pressure } \\
\text { after reposition } \\
{\left[\mathrm{cm} \mathrm{H}_{2} \mathrm{O}\right]} \\
\text { mean }\end{array}$ & $\begin{array}{l}\text { Functional urethral length } \\
\text { after reposition } \\
\begin{array}{c}{[\mathrm{mm}]} \\
\text { mean }\end{array}\end{array}$ \\
\hline OSUI $(n=19)$ & 400.1 & 0 & 237.6 & 39.7 & 21 \\
\hline No OSUI $(n=34)$ & 490.9 & 5.2 & 253.9 & 47.6 & 24 \\
\hline $\mathrm{p}$-value & n.s. & n.s. & n.s. & n.s. & n.s. \\
\hline
\end{tabular}

t-test for difference (OSUI vs. No OSUI), p-value $<.05$ significant

19 of the 53 women $(35.8 \%)$ who had a stress test with the prolapse reduced before surgery had a positive result and were therefore defined as occult stress incontinent. Postoperatively, $5(26.3 \%)$ of these 19 women with OSUI subjectively reported to be stress urinary incontinent. Only 3 of these 19 women $(15.8 \%)$ had a positive cough stress test and had to be operated because of SUI. No women without OSUI developed SUI postoperatively.

With respect to the patient group without urodynamic testing (180 women), 26/180 (14.4\%) complained of SUI postoperatively, and 15/180 (8.3\%) were operated because of SUI.

With respect to the entire patient group, 18/233 $(7.7 \%)$ complained of stress urinary incontinence 6 weeks to 6 months after surgery and received a TVTtape (Table 2, Fig. 1).

Table 3 summarizes the urodynamic parameters of women with and without OSUI preoperatively.

\section{Discussion}

The prevalence of occult stress urinary incontinence in our study is with $19 / 53(35.8 \%)$ comparable to the results of Gallentine et al., who reported about 50\% of women with severe genital prolapse to have OSUI (Gallentine et al. 2001). Furthermore the prevalence agrees with the results of Sinha et al., who examined 32 women with severe genitourinary prolapse using a ring pessary to reduce the prolapse, from which 10/32 developed symptoms of SUI (Sinha et al. 2007). However, although we diagnosed an OSUI in $35.8 \%$ of the women, only about one quarter of these women $(5 / 19,26.3 \%)$ reported to be stress urinary inconti- nent postoperatively. $3 / 19$ patients $(15.8 \%)$ in the subgroup with urodynamic testing and diagnosed OSUI, and $18 / 233$ women $(7.7 \%)$ of the entire patient group developed a SUI postoperatively which needed further surgical intervention.

There are different explanations for this discrepancy between preoperative OSUI and postoperative SUI. On the one hand, our preoperative testing might be not adequate. The repositioning of the prolapse using a speculum or a forceps could cause stress incontinence by traction on the posterior vaginal wall and the pelvic floor. On the other hand, the prolapse repair might work as an anti-incontinence surgery. All women received either an anterior colporrhaphy (with the vaginal approach) or a lateral colposuspension (with the abdominal approach). Bergman and co-authors showed a 5-year success rate of 37\% using the anterior colporrhaphy in the relief of stress incontinence (Bergman et al. 1995).

The small number of women $(18 / 233,7.7 \%)$ who needed secondary anti-incontinence procedure for postoperative SUI is in accordance with Beck et al., who reported that only $10 \%$ of continent women undergoing vaginal prolapse surgery without suspending urethropexy had stress incontinence (Beck et al. 1991). On the contrary however, there are several studies in which the prolapse repair was combined with a prophylactic incontinence surgery for OSUI and, despite the incontinence surgery, the rate of postoperative SUI (on average several years later) was higher: Bump et al. reported $14 \%$ of women developing SUI after needle colposuspension, Colombo et al. found SUI in $50 \%$ of all women after posterior pubourethral ligament plication, Gordon et al. in 50\% after Kelly plica- 
tion, Groutz et al. in $23 \%$ after Stamey procedure, and Meschia et al. in 44\% after plication of the endopelvic fascia. (Bump et al. 1996, Colombo et al. 1997, Gordon et al. 1999, Groutz et al. 2000, Meschia et al. 2004). Short-term data - as presented in our study are only available as failure rates of anti-incontinence procedures: For the first year after surgery, the Cochrane database reports a failure rate of $82 / 279$ $(29 \%)$ after anterior repair vs. 50/346 (14\%) after an open abdominal retropubic suspension. (Glazener et al. 2001)

A possible explanation for these differences might be that the follow up was on average several years in the above named studies compared to six months in our study. The short-term results, i.e. the success rates as anti-incontinence procedure, of the anterior colporrhaphy with $71 \%$ and the open abdominal retropubic suspension with $86 \%$ support the theory that the anterior repair serves as a (transient) incontinence procedure. Therefore we currently re-evaluate our patients with respect to SUI and prolapse recurrence in a longterm follow-up study.

The main result of our study is that the number of women who definitely need an anti-incontinence surgery after prolapse repair is very low, which is partially in contrary to Groutz et al., who state that the prophylactic TVT procedure is effective and safe in patients with OSUI undergoing prolapse repair (Groutz et al. 2004). It might be an "effective" procedure but, as shown in our study, one that is very often unnecessary. The known side effects and risks of this operation (including bladder perforation, hematoma, detrusor overactivity, voiding dysfunction / urinary retention, vaginal erosion) must be taken into account as well as its cost effectiveness. In Germany, the hospital is not reimbursed for an additional anti-incontinence procedure during prolapse surgery. This aspect should not decide about the operation strategy but it amplifies the arguments against a one-step approach.

However, we should not neglect those 26.3\% $(5 / 19)$ of our patients with preoperatively diagnosed OSUI who developed SUI after prolapse repair. Even though that subgroup is too small to draw any definite conclusions, we have to take into account that these women have to undergo a second surgery and probably would have had a benefit from concurrent incontinence surgery. Unfortunately, it is still not clear how to identify these patients before surgery.

The German society for gynaecology and obstetrics (DGGG) recommends a urodynamic testing before a prolapse surgery in their present guidelines (DGGG, 2008). On the one hand, we know that urodynamic testing is an invasive procedure and that $9.2 \%$ of the patients develop dysuria or a urinary tract infection after urodynamics (Lowder et al. 2007); on the other hand, the use of prophylactic antibiotics in urodynamics reduces the risk of significant bacteriuria (Latthe et al. 2008). Furthermore, urodynamic testing combined with a cough stress test provide us with information about an OSUI, bladder capacity, bladder compliance and urethral closure pressure. Therefore we identify women with OSUI, but we can not predict which of these patients develop SUI after prolapse repair.
Consequently, we should ask if we really need urodynamic testing before prolapse repair? As shown in Table 3, we could not find any significant differences of the preoperative urodynamic parameters between the patients with and without OSUI. We are not aware of any other studies reporting such differences. Only data about the urodynamic comparison of continent and incontinent women with severe uterovaginal prolapse exist (Long et al. 2004). Long and co-workers could show that clinically continent women with prolapse had a significant higher urethral closure pressure compared to incontinent controls; other parameters (e.g. maximum bladder capacity, incidence of bladder outlet obstruction and detrusor instability) did not differ.

On the one hand, if we decide to use a two-step approach and to do an incontinence operation after the prolapse repair only if necessary, it seems absolutely sufficient to perform a cough stress test and urodynamic testing after the prolapse repair and only if stress incontinence gets evident. On the other hand, for those $26.3 \%$ of women with preoperative OSUI who did develop SUI after surgery this approach seems not optimal since it would be desirable to identify them preoperatively.

However, as long as we do not have any method how to identify this subgroup, a possible strategy in women with prolapse could be: performing a cough stress test with repositioning to identify women with OSUI and afterwards continuing with urodynamic testing only in these women. A one-step approach can be discussed with these patients afterwards.

Possible limitations of our study are that our patient group is heterogeneous concerning the surgical approach (vaginally or abdominally), whether women were operated in a primary or recurrent situation, and that all women received an anterior repair, which might serve as an (at least transient) anti-incontinence surgery. Furthermore, the duration of the follow-up period could be seen as limitation: 6 months might be relatively short to decide about the prevalence of postoperative SUI; however, a longer follow-up period might increase the number of patients with recurrent prolapse of the anterior wall which might again mask the incontinence. To investigate the influence of the follow-up period on the results, a further follow up of these women is already ongoing.

In conclusion, our study shows that the prevalence of patients with stress urinary incontinence after prolapse repair is very low with $7.7 \%$ although occult stress urinary incontinence was demonstrated before surgery in $35.8 \%$. Therefore, a surgical two-step procedure appears justified if the patient is counseled and agrees. However, there is a small subgroup of women $(3 / 19,15.8 \%)$ with preoperative OSUI and SUI after surgery, who would benefit from a one-step approach. Further research is required to identify these women before surgical intervention.

Acknowledgement: We would like to thank Thomas Zwingers (estimate $\mathrm{GmbH}$, Gesellschaft für Planung und Durchführung von Forschungsvorhaben in der Medizin und im Gesundheitswesen $\mathrm{mbH}$ ) for statistical support.

Conflict of Interests: none 


\section{REFERENCES}

1. Beck RP, McCormick S, Nordstrom L. A 25-year experience with 519 anterior colporrhaphy procedures. Obstet Gynecol 1991;78:1011-8.

2. Bergman A, Elia G. Three surgical procedures for genuine stress incontinence: five-year follow-up of a prospective randomized study. Am J Obstet Gynecol 1995; 173:66-71.

3. Bump RC, Hurt WG, Theofrastous JP, Addison WA, Fantl JA, Wyman JF, McClish DK. Randomized prospective comparison of needle colposuspension versus endopelvic fascia plication for potential stress incontinence prophylaxis in women undergoing vaginal reconstruction for stage III or IV pelvic organ prolapse. The Continence Program for Women Research Group. Am J Obstet Gynecol 1996;175(2):326-33.

4. Bump RC, Mattiasson A, Bo K, Brubaker LP, DeLancey JO, Klarskov P et al. The standardization of terminology of female pelvic organ prolapse and pelvic floor dysfunction. Am J Obstet Gynecol 1996;175:10-17

5. Colombo M, Maggioni A, Scalambrino S, Vitobello D, Milani R. Surgery for genitourinary prolapse and stress incontinence: a randomized trial of posterior pubourethral ligament plication and Pereyra suspension. Am J Obstet Gynecol. 1997;176(2):337-43.

6. de Tayrac R, Gervaise A, Chauveaud-Lambling A, Fernandez H. Combined genital prolapse repair reinforced with a polypropylene mesh and tension-free vaginal tape in women with genital prolapse and stress urinary incontinence: a retrospective case-control study with short-term follow-up. Acta Obstet Gynecol Scand 2004;83:950-954.

7. Descensus genitalis der Frau - Diagnostik und Therapie. AWMF 015/006 (S2k). Deutsche Gesellschaft für Gynäkologie und Geburtshilfe. Leitlinien. Stand August 2008.

8. Gallentine ML, Cespedes RD. Occult stress urinary incontinence and the effect of vaginal vault prolapse on abdominal leak point pressures. Urology. 2001;57(1):40-4.

9. Glazener CM, Cooper K. Anterior vaginal repair for urinary incontinence in women. Cochrane Database Syst Rev. 2001;(1):CD001755.

10. Gordon D, Groutz A, Wolman I, Lessing JB, David MP. Development of postoperative urinary stress incontinence in clinically continent patients undergoing prophylactic Kelly plication during genitourinary prolapse repair. Neurourol Urodyn. 1999;18(3):193-7; discussion 197-8.

11. Groutz A, Gold R, Pauzner D, Lessing JB, Gordon D. Tension-free vaginal tape (TVT) for the treatment of occult stress urinary incontinence in women undergoing prolapse repair: a prospective study of 100 consecutive cases. Neurourol Urodyn. 2004;23(7):632-5.

12. Groutz A, Gordon D, Wolman I, Jaffa AJ, Kupferminc MJ, David MP, Lessing JB. The use of prophylactic Stamey bladder neck suspension to prevent post-operative stress urinary incontinence in clinically continent women undergoing genitourinary prolapse repair. Neurourol Urodyn. 2000;19(6):671-6.
13. Hextall A, Boos K, Cardozo L, Toozs-Hobson P, Anders K, Khullar V. Videocystourethrography with a ring pessary in situ. A clinically useful preoperative investigation for continent women with urogenital prolapse? Int Urogynecol J Pelvic Floor Dysfunct. 1998;9(4):205-9.

14. Karram MM Urodynamics; cystometry, voiding studies, urethral pressure profilometry. In: Walters MD, Karram MM (eds) Clinical urogynecology. Mosby, St. Louis, 1993:62-101

15. Klutke JJ, Ramos S. Urodynamic outcome after surgery for severe prolapse and potential stress incontinence. Am J Obstet Gynecol 2000;182:1378-1381.

16. Latthe PM, Foon R, Toozs-Hobson P. Prophylactic antibiotics in urodynamics: a systematic review of effectiveness and safety. Neurourol Urodyn. 2008;27(3):167-73.

17. Long CY, Hsu SC, Wu TP, Sun DJ, Su JH, Tsai EM. Urodynamic comparison of continent and incontinent women with severe uterovaginal prolapse. J Reprod Med 2004; 49:33-37

18. Lowder JL, Burrows LJ, Howden NL, Weber AM. Prophylactic antibiotics after urodynamics in women: a decision analysis. Int Urogynecol J Pelvic Floor Dysfunct. 2007;18(2):159-64. Epub 2006 May 4.

19. Meschia M, Pifarotti P, Spennacchio M, Buonaguidi A, Gattei U, Somigliana E. A randomized comparison of tension-free vaginal tape and endopelvic fascia plication in women with genital prolapse and occult stress urinary incontinence. Am J Obstet Gynecol. 2004;190(3):609-13.

20. Romanzi LJ. Management of the urethral outlet in patients with severe prolapse. Curr Opin Urol. 2002;12(4): 339-44.

21. Roovers JP, Oelke M. Clinical relevance of urodynamic investigation tests prior to surgical correction of genital prolapse: a literature review. Int Urogynecol J Pelvic Floor Dysfunct. 2007;18(4):455-60. Epub 2006 Nov 22.

22. Schüssler B, Alloussi S. Zur Klassifikation der Stressinkontinenz nach Ingelman-Sundberg. Gynäkog Rdsch 1983; 23:166-174.

23. Sinha D, Arunkalaivanan AS. Prevalence of occult stress incontinence in continent women with severe genital prolapse. J Obstet Gynaecol. 2007;27(2):174-6.

Received: October 15, 2009 / Accepted: February 10, 2010

Address for correspondence:

Katharina Jundt, MD

Department for Gynecology and Obstetrics

Ludwig-Maximilians-Universität

Maistr. 11

80337 Munich

Germany

Phone: +49-89-5160-4111

Fax: +49-89-5160-4166

E-mail: katharina.jundt@med.uni-muenchen.de 